\title{
Gamma amino-butyric acid and the control of GnRH secretion in sheep
}

\author{
J. E. Robinson \\ Laboratory of Neuroendocrinology, Department of Neurobiology. The Babraham Institute, \\ Babraham, Cambridge CB2 4AT, UK.
}

\begin{abstract}
The release of GnRH from nerve terminals in the median eminence into the portal vessels is influenced by factors in the internal and external environment of the animal. In the former category are the gonadal steroid hormones oestrogen and progesterone which alter the characteristics of $\mathrm{GnRH}$ secretion during the oestrous and seasonal cycles. These cannot exert their actions directly on the GnRH neurones as they do not possess hormone receptors. Therefore, some other steroid-sensitive neuronal system must relay this information to the GnRH neurones. Gamma amino-butyric acid (GABA) neurones are good candidates for this role as they contain steroid hormone receptors and synapse on GnRH neurones. Recent studies in ewes have sought to identify a role for GABA in mediating the actions of both oestrogen and progesterone on GnRH release. The technique of microdialysis was used to monitor GABA concentrations in areas containing $\mathrm{GnRH}$ cell bodies during the oestrogen-induced surge of $\mathrm{GnRH}$ and during progesterone negative feedback. Concentrations of this inhibitory neurotransmitter have been shown to fall in the former situation where $\mathrm{GnRH}$ release is being stimulated, but to be increased when progesterone is depressing GnRH release. GABA may also be important in mediating the seasonal switch in the negative feedback actions of oestradiol. During the anoestrous season, when oestradiol is a potent inhibitor of $\mathrm{GnRH}$ secretion, specific GABA receptor antagonists can stimulate neurohormone release, an action that is not observed in the breeding season when oestrogen is much less potent.
\end{abstract}

\section{Introduction}

Despite extensive studies in several species, using a range of technical approaches, we still do not understand the neural mechanisms that control the release of LH from the pituitary gland Substantial progress has been made and several components that play key roles in the secretion of this hormone have been identified. Central to this are the neurones that manufacture and secrete gonadotrophin releasing hormone $(\mathrm{GnRH})$ into the portal vessels to stimulate LH secretion. In sheep these cells are not located in a discrete cell group (or nucleus), but in a continuum from the septum to the mediobasal hypothalamus. However, most GnRH cell bodies are located in the preoptic area (POA), in an "inverted $Y^{\prime}$ formation, close to the midline (Lehman et al., 1986; Caldani et al., 1988) from where they project to the median eminence (ME). These scattered neurones are, by some unknown mechanism, coordinated to release their neurohormone as a discrete bolus (Clarke and Cummins, 1982; Caraty and Locatelli, 1988), and the characteristics of this secretion are influenced by both intrinsic (for example steroid hormones) and extrinsic (for example photoperiod) factors, some of which are discussed in depth in this supplement.

Gonadal steroid hormones are known to influence the characteristics of LH secretion. This has been demonstrated during the oestrous cycle (Karsch et al. 1980), the generation of the preovulatory LH 
surge (Kaynard et al., 1988) and the seasonal reproductive cycle (Legan and Karsch, 1980). It has become clear that this action occurs, in part, in the brain to alter the release of GnRH from nerve terminals in the ME into the portal vessels (Karsch et al., 1987, 1993). However, the genomic actions of steroids are unlikely to be directly on the GnRH neurones. Although there are many oestrogen receptorimmunoreactive cells in the POA (Herbison et al., 1993; Lehman et al., 1993; Blache et al., 1994), they are not located in the GnRH neurones themselves (Herbison et al., 1993; Lehman and Karsch, 1993). Therefore, this action must be mediated by other steroid-sensitive neuronal systems. There are several candidates for this role (see Herbison, this supplement), including neurones containing the inhibitory amino acid neurotransmitter gamma amino-butyric acid (GABA). In ewes, GABA interneurones in the preoptic area possess receptors for oestrogen (Herbison et al., 1993; see Herbison, Fig. 2, this supplement) and form synaptic connections with local GnRH neurones (Karsch et al, 1989). The studies outlined in this review were designed to explore the role of GABA in the steroidal control of $\mathrm{LH}$ secretion in this seasonally breeding species.

\section{The Oestrogen-induced LH Surge}

After the administration of concentrations of oestrogen in the high physiological range, GnRH neurones respond with a massive, sustained release of GnRH into the portal vessels. The neural events that culminate in this GnRH surge remain unresolved for any species and the sheep may prove a key experimental animal in these types of study for three main reasons. First, it is the only species in which the characteristics of GnRH secretion during the surge are well described. Thus, we are well aware that the LH surge is driven by a surge of $\mathrm{GnRH}$ that rises simultaneously, but falls substantially later than that of LH (Moenter et al., 1990). Second, the large brain of the sheep makes it possible to target relatively discrete neural sites for particular manipulations, or for the sampling of neurotransmitters in vitro or in vivo. Finally, because of the discontinuous nature of reproduction in this species and, because methods to manipulate this hormonally or with specific light treatments are well understood, it is possible to make comparisons between reproductively active and inactive animals or to follow events when an animal is stimulated into or out of breeding condition.

Because of the considerations outlined above, we are currently using sheep in our studies of the neural control of GnRH secretion. We have adapted and developed the technique of microdialysis coupled to sensitive detection systems (high performance liquid chromatography with electrochemical or fluorescence detection) to sample the concentrations of several neurotransmitters in the extracellular fluid compartment of discrete regions of the brain. This technique allows GABA concentrations to be monitored in the brain region containing the GnRH cell bodies of conscious, freely moving ewes during a surge of GnRH (Robinson et al, 1991). During this study, surges of LH were generated during the anoestrous season in seven ovary-intact ewes, of the Clun Forest breed, by subcutaneous administration of capsules of oestradiol. This manipulation results in a massive release of LH $13-15 \mathrm{~h}$ after the introduction of the steroid (Fig. 1). Concentrations of GABA were found to be high initially after the administration of oestrogen, but fell some hours before the surge to reach minimal values just before the first increase in LH (and, therefore, GnRH) secretion. In contrast, this pattern was not seen when GABA concentrations were monitored in the same neural site during a control period when oestrogen was not administered and LH concentrations remained low. Similar profiles of release of GABA from the POA have been obtained in rats in the hours immediately before the circadian based LH surge using a modified 'push-pull' technique (Demling et al., I985; Jarry et al., 1988a). These data suggest that, in both species, inhibitory GABA-ergic tone is greatly reduced in the hours before the surge. Such correlative studies are strengthened by the finding that infusions of GABA either into the third ventricle (Morello et al., 1989) or directly into the POA (Herbison and Dyer, 1991) just before the expected rise in LH secretion can block the surge in rats. In addition, expression of mRNA for glutamic acid decarboxylase, the synthetic enzyme for GABA, is reduced in the rat POA before the onset of the LH surge (Herbison et al., 1992). No studies using GABA or specific receptor agonists or antagonists to block, or otherwise alter, the timing of the ovine LH surge have been published, but would add substantially to our understanding of the neural mechanisms controlling this event in ewes. Further work is also needed to 

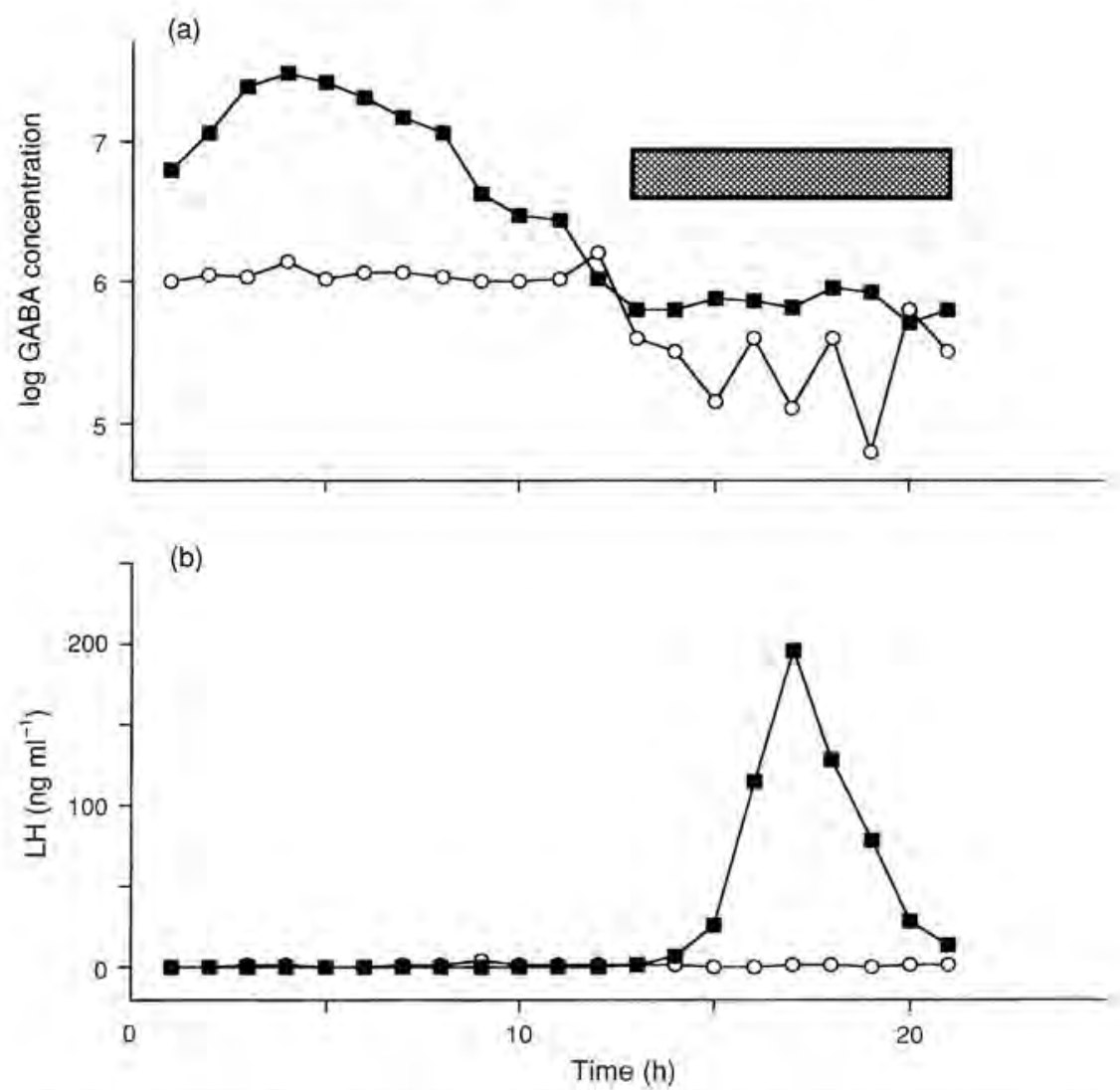

Fig. 1. The preovulatory surge of LH. Associated changes in the concentrations of (a) log gamma amino butyric acid (GABA) concentrations in the preoptic area as measured by microdialysis and (b) LH ( $\mathrm{ng} \mathrm{ml}^{-1}$ ). Surges were generated in seven ovary-intact ewes by the adininistration of oestradiol $2-3 \mathrm{~h}$ before sample collection began. Samples of jugular venous blood and dialysis outflow were collected at intervals of $20 \mathrm{~min}$ and assayed for (a) GABA and (b) $\mathrm{LH}$, respectively. Data were divided into hourly periods for presentation; ( concentrations during a surge and $(O)$ concentrations during a control period (when no oestrogen was given and no surge occurred). The horizontal bar in (a) represents the time of increased LH during the surge. Adapted from Robinson et al. (1991).

identify the receptor subtypes in the vicinity of and within the GnRH cell bodies. In rats, GABA receptors are more numerous than are $\mathrm{GABA}_{\mathrm{B}}$ receptors in the hypothalamus (Gehlert et al., I985). It would be of interest to determine whether the proportion of the different receptor subtypes changed with the steroidal status of the animal.

Another, mainly technical, challenge will present itself in the very near future. It is becoming increasingly important to be able to monitor $\mathrm{GnRH}$ secretion directly (rather than inferring the pattern of secretion from peripheral LH measurements) while simultaneously measuring neurotransmitter concentrations (or performing other neural manipulations). This has not been possible, mainly because the technique of portal blood collection requires that animals are heavily heparinized. It will be of great value either to resolve this technical difficulty in sheep, or to develop another method or approach to monitor $\mathrm{GnRH}$ release which has equally good temporal resolution. This combined technology will also be important when resolving the mechanism by which the GnRH surge is terminated, as concentrations of neurohormone are known to fall several hours after fhose of LH (Moenter et al., 1990). This event has received scant attention. We have recently monitored GABA release in the POA throughout, and for several hours after, the LH surge, until a time when we predicted that the GnRH surge should have 
terminated (A. Caraty and J. E. Robinson, unpublished). We reasoned that if a fall in GABA is necessary for the initiation of the surge, concentrations might rise once more to terminate the event. However, we have found no evidence for a change in GABA concentrations in the POA at a time when we estimate the GnRH surge should have ended. This observation suggests that the neural mechanism that terminates the surge is not simply the reverse of that by which it was initiated.

\section{Progesterone Negative Feedback}

Although abrupt increases in circulating progesterone can contribute to the generation of the LH surge in several species (Clifton et al., 1975), this does not appear to be the case in sheep, in which progesterone is strictly inhibitory. Progesterone plays a very important neuroendocrine role in ewes and can be considered as the 'organizer' of the oestrous cycle. It is evident that this action is predominantly central. Thus, when progesterone concentrations are high during the luteal phase of the cycle, the frequency of GnRH pulses is low (Barrell ef al. 1992). The fall in progesterone concentrations after luteolysis allows pulse frequency to rise (Barrell et al., 1992) and be stimulated further by rising concentrations of oestrogen. However, if high physiological concentrations of progesterone are maintained artificially, GnRH pulse frequency cannot increase and the preovulatory surge is blocked (Kasa-Vubu et al., I992).

By what neural mechanism can progesterone exert its inhibitory actions? Although our knowledge is scant, it appears that this steroidal blockade is associated with a lack of the normal expression of the immediate early gene c-fos in GnRH neurones (Lehman et al., 1992; Moenter et al., 1993). Because there are no progesterone receptors in rat GnRH neurones (Fox et al, 1990) and as ovine GnRH neurones do not have either oestrogen or androgen receptors (Herbison, this supplement), we assume that they also lack receptors for progesterone. Therefore, the effects of this ovarian hormone are, most probably, mediated by neural systems that impinge on GnRH cells. It is known that progestin receptors are found in regions of $\mathrm{GnRH}$ neurones, although the chemical identity of the neurones containing them is currently unknown (Bittman and Blaustein, 1990). The possibility that GABA neurones are involved in this steroidal action arises because studies in guinea-pigs have shown that progesterone receptors are present in neurones that are also oestrogen receptive (Blaustein and Turcotte, 1989; Warembourg et al., 1989).

A role for $G A B A$ in the inhibition of $\mathrm{GnRH}$ release by this steroid was explored by measuring changes in the concentrations of neurotransmitter in the POA (by microdialysis) under conditions of progesterone negative feedback. Progesterone was administered to ovariectomized ewes in the mid-breeding season via subcutaneous implants to produce circulating concentrations similar to those of the luteal phase. These concentrations significantly depressed mean LH concentrations (Fig. 2a, b) and this inhibition was associated with a significant increase in the concentrations of GABA in the POA. This finding provides the first evidence that the central actions of progesterone may involve GABA neurones in regions of $\mathrm{GnRH}$ perikarya, and that this neural system may play a key role in the organization and timing of events in the ovine oestrous cycle. Furthermore, as an earlier study (see above) concluded that concentrations of this inhibitory neurotransmitter were reduced before the LH surge, the mechanism by which progesterone can block this event may involve maintaining high local concentrations of GABA. It will also be of interest to determine the neural events that result from the withdrawal of progesterone following luteolysis, Could these contribute to a reduction in the release of GABA before the natural LH surge?

Although, as stated earlier, there are progesterone receptors in the ovine POA (Bittman and Blaustein, 1990), the precise neurones in which they are located are unknown. Thus, although the action of progesterone on GABA release in this region may be direct, it may equally well be via another neural system. We chose to determine whether the endogenous opioid peptides play a role, In rats, $\beta$-endorphin-immunopositive neurones have been shown to contain progesterone receptors (Fox et al., 1990) and there is good evidence that the endogenous opioid peptides are involved in progesterone negative feedback in ewes (Trout and Malven, 1987, Yang et al., 1988; Currie et al., 1991). Thus, at the end of the previous study, the same ewes were infused $i, v$. with the long-acting opioid antagonist, 

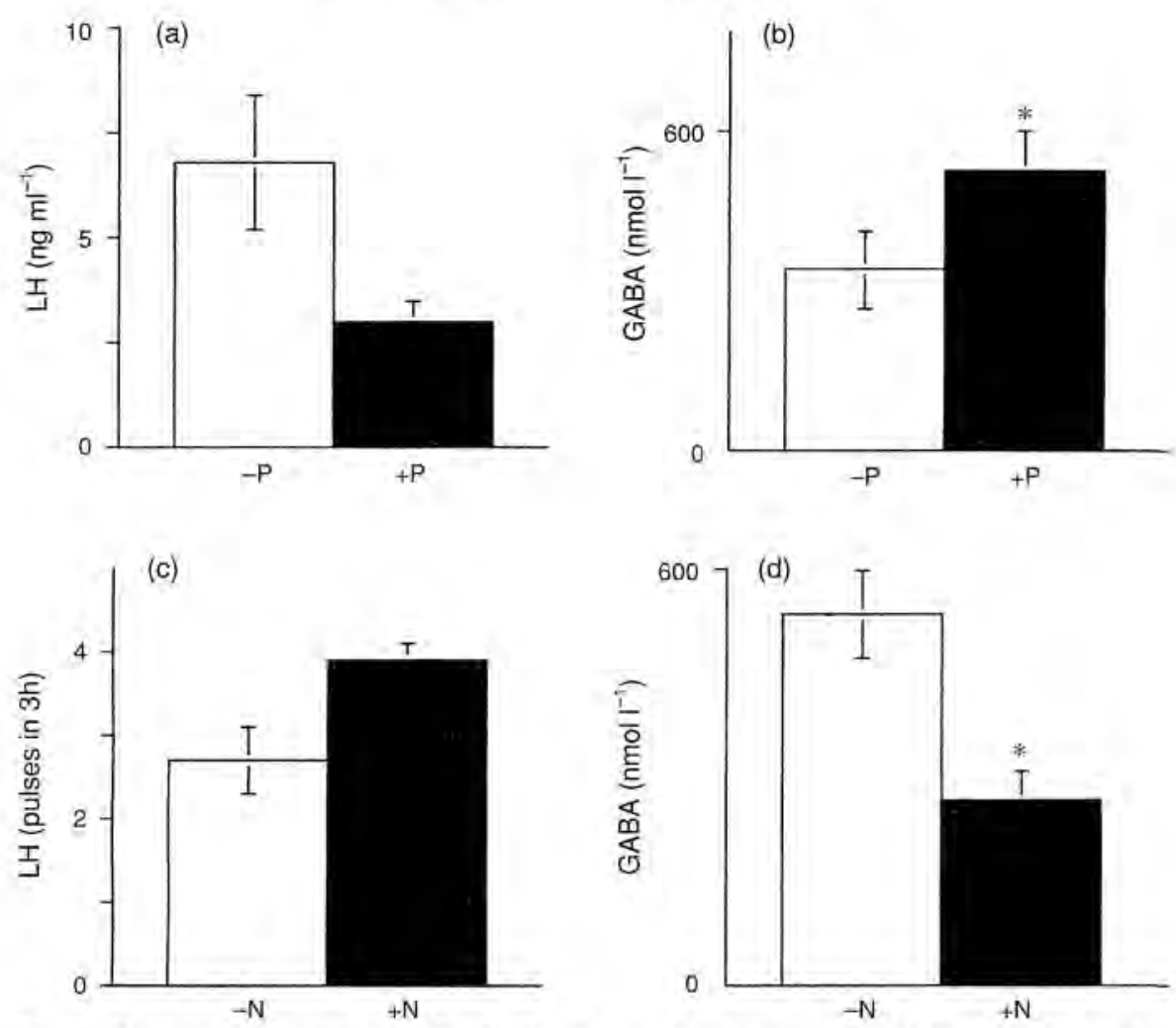

Fig. 2. Progesterone negative feedback. The action of progesterone to inhibit (a) LH secretion (ng $\mathrm{ml}^{-1}$ ) is associated with a significant increase in (b) gamma amino butyric acid (GABA) concentrations $\left(\mathrm{nmol} 1^{-1}\right)$ in the preoptic area (POA), $(\square)$ : Concentrations during $3 \mathrm{~h}$ before the introduction of progesterone $(-\mathrm{P}, \mathrm{a} \text { and } \mathrm{b})_{;}$and $(\mathbf{W})$ over $3 \mathrm{~h}$ in the presence of progesterone $(+\mathrm{P}, \mathrm{a}$ and $\mathrm{b})$. In the presence of progesterone the opioid antagonist, naltrexone $(+N)$ stimulated LH pulse frequency (c) and GABA concentrations were significantly reduced (d). $n=5$; values represent means \pm SEM. Adapted from Robinson and Kendrick (1992).

naltrexone while LH and GABA concentrations were monitored (Robinson and Kendrick, 1992). As expected, naltrexone significantly increased the frequency of $\mathrm{LH}$ pulses in the presence, but not the absence, of progesterone. This gonadotrophic stimulation was associated with a suppression of GABA concentrations (Fig. 2c, d). Once again we have a situation in which there is an inverse relationship between GnRH and GABA concentrations; GABA concentrations in the POA are low when LH/GnRH concentrations are high and vice versa. These correlative data support an inhibitory role for GABA in the control of LH secretion in ewes. They also suggest that the action of progesterone to increase GABA concentrations in the POA is mediated via an (indirect?) action on the endogenous opioids. Before the LH surge, opioid tone (like that of GABA) has been shown to decline (Allen and Kalra, 1986). The interaction of the GABA and opioid systems to mediate the actions of ovarian steroids on LH secretion could prove a fruitful area for future research.

\section{Seasonal Alterations in Negative Feedback by Oestradiol}

Although progesterone might be regarded as the orchestrator of the oestrous cycle, oestrogen is the ovarian hormone responsible for the seasonal alterations in tonic LH secretion (Legan and Karsch, 1980; Goodman et al, 1982; Thomas et al., 1988). In the non-breeding season a physiological concentration of 
oestrogen is a potent inhibitor of LH release, while similar concentrations are markedly less effective in the breeding season. The assumption that the actions of oestrogen are central was given recent experimental support (Karsch et al., 1993) by the direct measurement of GnRH in the portal blood after the implantation of constant-release capsules of oestradiol into ovariectomized ewes in either season. Thus, during the breeding season low oestrogen concentrations did not alter the characteristics of pulsatile GnRH release, whereas profound suppression resulted in anoestrus. This finding shows that, during the non-breeding season, the brain is exquisitely sensitive to this steroid hormone. Fundamental to our understanding of the neural events that can cause this marked change in response to negative feedback by oestradiol is the identification of steroid-sensitive (inhibitory?) neuronal populations that seasonally alter the activity of GnRH neurones. Once again GABA appears to be an excellent candidate.

In 1985, Meyer and Goodman screened several neurotransmitter antagonists in an initial attempt to determine the neural systems that suppress $\mathrm{LH}$ release in anoestrus. Bicuculline (a $G A B A_{A}$ receptor antagonist) was administered i.v. but failed to alter LH release significantly, despite having obvious behavioural effects. Recent studies using a central route of administration of specific GABA receptor agonists and antagonists have concluded that this inhibitory neurotransmitter may be involved in the seasonal changes in oestradiol negative feedback (Scott and Clarke, 1993a,b). In these studies activity at both the $\mathrm{GABA}_{\mathrm{A}}$ and $\mathrm{GABA} \mathrm{B}_{\mathrm{B}}$ receptors was altered by microinjection of high concentrations of specific receptor agonists and antagonists directly into the POA of ovariectomized and ovariectomized, oestrogen-treated ewes in both seasons and the actions on tonic LH secretion evaluated. The results of these manipulations were complicated and, therefore, rather difficult to interpret. However, alterations in activity at the $\mathrm{GABA}_{\mathrm{A}}$ receptor had effects that depended on the degree to which oestrogen inhibited $\mathrm{LH}$ release. When oestrogen unambiguously suppressed LH release in anoestrus, local injection of bicuculline stimulated gonadotrophin secretion. In contrast, in the breeding season, in the absence of steroid and in situations in which oestradiol did not markedly inhibit LH, this antagonist inhibited gonadotrophin release. These results suggest that $\mathrm{GABA}_{\mathrm{A}}$ receptors in the POA may be involved in oestrogen-negative feedback in the non-breeding season but not in the breeding season and, therefore, be of critical importance in the photoperiodic control of seasonality in this species. Additional studies, in both ewes and rams of different breeds (and different sensitivities to steroid negative feedback), will be necessary to identify the precise role of GABA in mediating steroidal negative feedback inhibition of GnRH secretion. Of further interest in the studies of Scott and Clarke was the observation that bicuculline stimulated a non-pulsatile release of LH in anoestrous ewes. It will be necessary to extend these studies and to identify the underlying profile of $\mathrm{GnRH}$ release to determine whether this antagonist disrupted the discrete episodes of neurohormone secretion. Such an observation might indicate that GABA plays a critical role in the synchronization of GnRH neurones, as has been suggested in rats (Herbison et al., 1991; Jarry et al., 1991).

\section{GABA and the Generation of GnRH Pulses}

One of the fundamental questions in neuroendocrinology is how discrete episodes of hormone are released from the pituitary gland. In the case of $\mathrm{LH}$, we appreciate that this is in response to the episodic release of $\mathrm{GnRH}$. However, the mechanisms by which these neurones are synchronized to produce a pulse of neurohormone in the portal vessels has yet to be elucidated. As release of several neurotransmitters that have been implicated in the control of $\mathrm{LH}$ release also appear to be episodic (Demling et al., 1985; Jarry et al., 1988b; Terasawa et al., 1988; Dietl et al., 1993), it is possible that GnRH pulses occur as a direct consequence of the intermittent activation of these neurones. In rats, two separate groups have sought to determine whether there are temporal correlations between POA concentrations of GABA and peripheral LH release. The results of these studies are conflicting. Thus, Jarry et al. (1988a), using a modified push-pull method to collect samples of extracellular fluid, reported a fall in GABA release before an episode of LH release, whereas Herbison et al. (1991) were unable to repeat this result using microdialysis.

In a recent study (I. J. Clarke and J. E. Robinson, unpublished) we aimed to resolve this issue by performing similar studies in ewes. Because of their larger brains, we hoped to target a more discrete area 


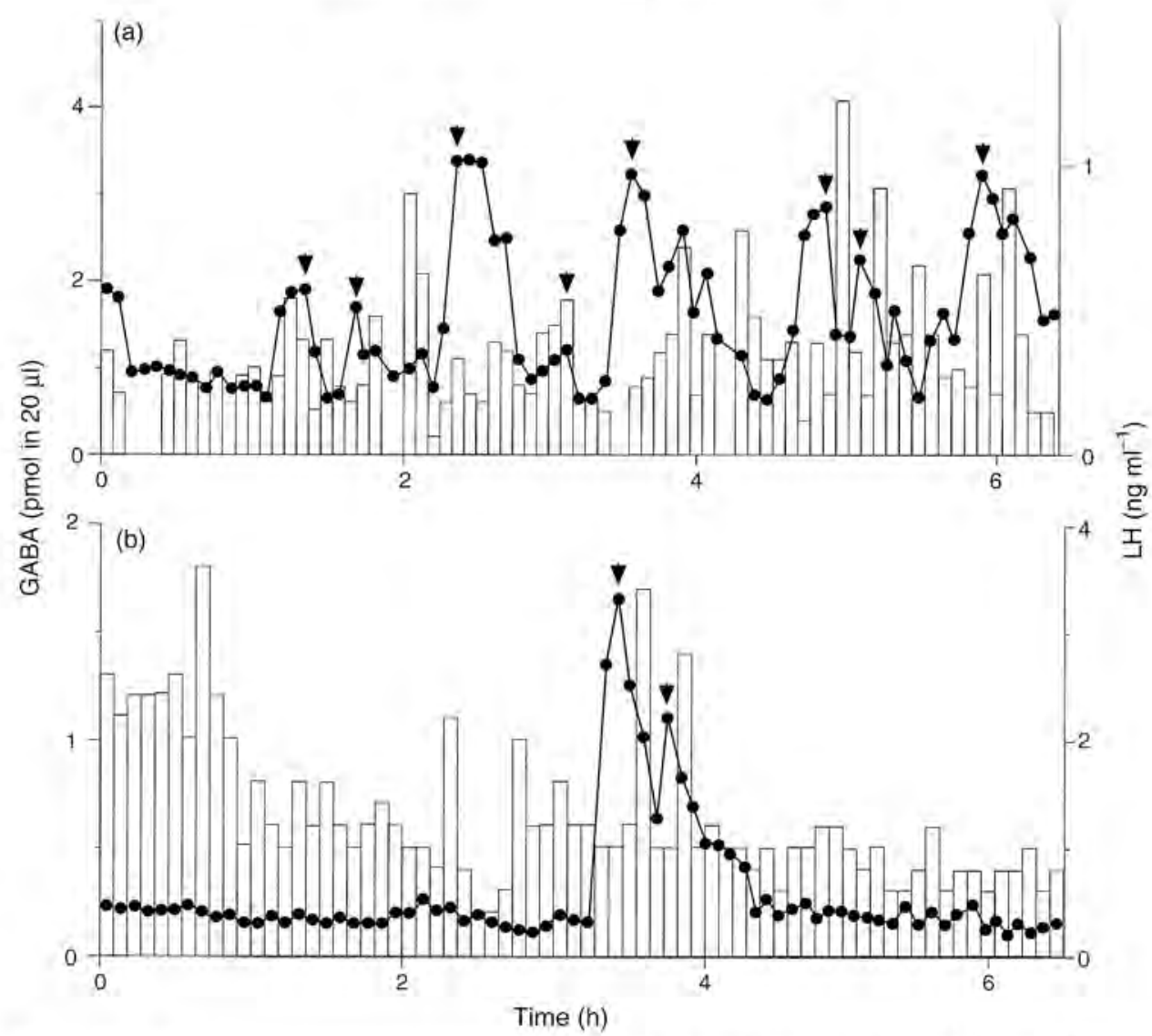

Fig, 3. Episodic secretion of gamma amino butyric acid (GABA) and LH. Samples of blood and dialysis outflow were collected from the preoptic area (POA) at intervals of 5 min during either (a) the follicular phase or (b) the luteal phase. Examples of the temporal relationship between pulses of LH (•) and GABA ( $\square$ ) are shown for two individual ewes. Pulses of LH, identified by the method of Clifton et al. (1988) are indicated by black arrowheads.

for sampling than had been possible in the studies in rats. Samples of dialysis outflow were collected from the POA of six ewes during the breeding season. Each ewe was sampled on two occasions, once during the follicular phase and once during the luteal phase (cycles synchronized with prostaglandin). Samples of jugular blood and dialysis outflow were collected at intervals of $5 \mathrm{~min}$ for between 6 and $7 \mathrm{~h}$ and correlations between $\mathrm{LH}$ and GABA release determined. As in rats, the release of GABA was remarkably episodic (see Fig. 3) with pulses of neurotransmitter occurring throughout the sampling period and at both times of the oestrous cycle. Our results and conclusions were similar to those of Herbison et al. (1991). Thus, although in a few situations there appeared to be a temporal association between pulses of LH and GABA, the overall picture did not reveal a significant correlation. Of course, this negative result does not rule out a role for GABA in the generation of a pulse of LH. It may give more information about the limitations of the technique used to sample neurotransmitters from the brain and a different approach might be more appropriate to study the interaction between GABA and GnRH neurones in the control of episodic LH secretion.

Evidence suggests that a short-loop feedback, involving GnRH neurones, may be critical for the pulsatile release of this neurohormone. Thus, in ewes, central infusion of $\mathrm{GnRH}$ has been shown to inhibit the release of LH (Naylor et al., 1989). This inhibitory action of GnRH on its own secretion might involve interaction among the $\mathrm{GnRH}$ neurones or, perhaps, reciprocal connections between $\mathrm{GnRH}$ and 


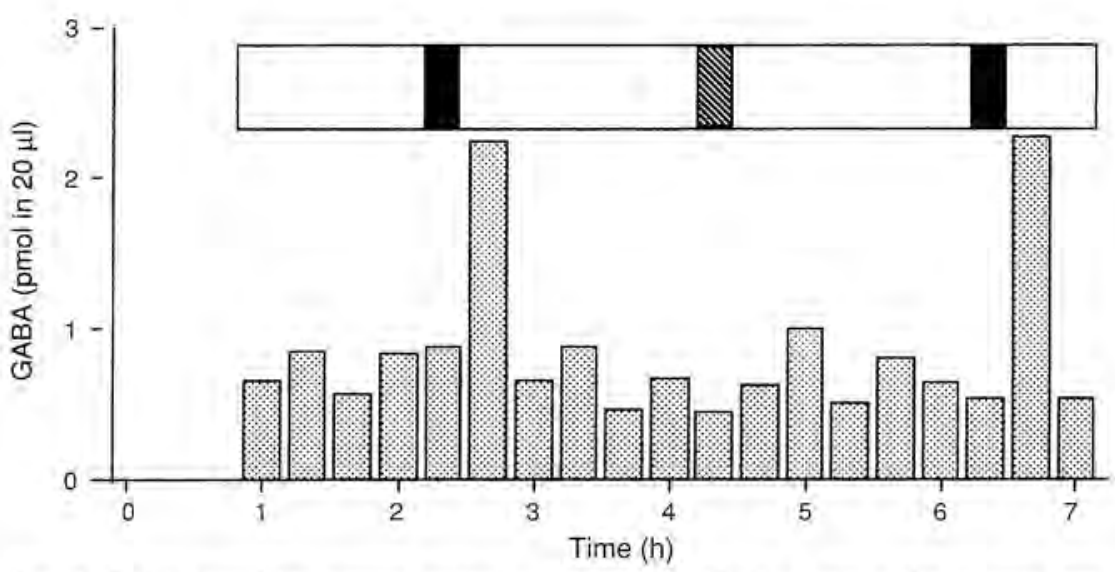

Fig. 4. GnRH stimulates gamma amino butyric acid (GABA) release in the preoptic area (POA). The response of GABA (口) to infusion of $10^{-0} \mathrm{mmol} \mathrm{GnRH} \mathrm{l}^{-1}$ into the POA via a microdialysis probe. GnRH was infused for $20 \mathrm{~min}$ on two occasions (- with an intervening period of infusion of a fragment of the GnRH molecule (amino acids 3-10; 1 ).

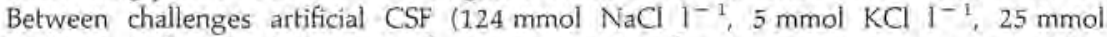
$\mathrm{NaHCO}_{3} \mathrm{1}^{-1}, 5 \mathrm{mmol}$ glucose $\left.1^{-1}, 2 \mathrm{mmol} \mathrm{CaCl}_{2} \mathrm{1}^{-1}: \mathrm{pH}=7.4\right)$ was pumped round the probe (五). Samples were collected for $20 \mathrm{~min}$ and analysed by HPLC with fluorescence detection.

other local neurones such as GABA. In sheep, GABA neurones have been shown to form synaptic connections with GnRH neurones (Karsch et al, 1989) and if GnRH could be shown to alter local GABA release then the neural substrate for a feedback loop would exist. Furthermore, as one element of the loop (the GABA neurones) is sensitive to oestrogen, this might be a route by which steroids exert actions on pulsatile GnRH secretion. We have been exploring a connection between these neural systems by infusing GnRH directly into the POA and monitoring the response of the local GABA neurones (Robinson et al, 1993). When $\mathrm{GnRH}\left(10^{-\sigma} \mathrm{mol} \mathrm{l}^{-1}\right)$ was infused via a microdialysis probe for $3 \mathrm{~h}$ we found that GABA concentrations were significantly raised in the first sample ( $20 \mathrm{~min}$ intervals) after infusion began. In subsequent experiments, the neurohormone was infused for a much shorter period ( $20 \mathrm{~min}$ ) and the results from an individual ewe are shown in Fig. 4. Two 'pulses' of GnRH were administered $4 \mathrm{~h}$ apart and resulted in prompt and substantial increases in GABA release. In contrast, when a fragment of the molecule (amino acids 3-10) was infused in the intervening period this failed to stimulate a similar response. Although these studies are not complete, they provide preliminary evidence for reciprocal connections between $\mathrm{GnRH}$ and GABA neurones in the POA. Useful additional data would be provided by studies at the electron microscope level showing GnRH synapses on GABA neurones. The existence of this feedback loop might help to explain some of our observations on the secretion of this releasing hormone. For example, it has been noted that just before the LH surge, discrete $\mathrm{GnRH}$ pulses become progressively less distinct as basal release rises and pulse duration increases (Evans et al., 1993). At this time, local GABA concentrations have declined, thus altering the characteristics of the feedback loop. This might result in reduced synchrony among the GnRH neurones which is, potentially, a necessary component of the preovulatory surge. Although these ideas are highly speculative, they may serve as a focus for future experimental work.

\section{Conclusions}

Although there is good evidence that GABA neurones in the POA are part of the neural network controlling $\mathrm{LH}$ secretion in rats, a strong case has yet to be made for any other species, including sheep. Because of the critical role that steroid hormones play in the central control of both the oestrous and seasonal cycles, ewes are ideal experimental animals in which to determine the potential interactions 
among the ovarian steroids, GABA and GnRH. An important initial step has been to establish that GABA neurones synapse on GnRH perikarya. Furthermore, these neurones possess receptors for oestrogen. Concentrations of GABA in this region have been demonstrated to change during a surge of $\mathrm{LH}$ which was induced by exogenous oestradiol. GABA release is also altered during negative feedback by progesterone. In addition, recent studies suggest that this inhibitory neurotransmitter may be important in mediating seasonal changes in the potency of negative feedback by oestradiol and in the process by which GnRH neurones are synchronized to release neurotransmitter as a discrete bolus.

The author would like to acknowledge the staff at the Babraham Institute who participated in the experimental work, especially K. Kendrick, A. Herbison, R. Dyer, D. Skinner, C. Chapman and J. Yates. In addition, A. Herbison gave critical evaluation of an earlier version of the manuscript. The National Hormone Pituitary Program provided reagents for the radioimmunoassay.

\section{References}

Allen LG and Kalra SP (1986) Evidence that decrease in opioid tone may provoke preovulatory luteinizing hormone release in the rat Endocrinology 118 2375-2381

Bittman EL and Blaustein ID (1990) Effects of day length on sheep neuroendocrine estrogen and progestin receptors American Joumal of Physiology 258 R $135-R 142$

Barrell GK Moenter SM, Caraty A and Karsch FJ (1992) Seasonal changes of gonadotropin-releasing hormone secretion in the ewe Biology of Reproduction 46 1130-1135

Blache D, Batailler M and Fabre-Nys C (1994) Oestrogen receptors in the preoptic-hypothalamic continuum: immunohistochemical study of the distribution and cell density during induced oestrous cycle in ovariectomized ewe Journal of Neuroendocrinology 6 329-339

Blaustein JD and Turcotte JC (1989) Estradiol-induced progestin receptor immunoreactivity is found only in estrogen receptor-immunoreactive cells in guinea pig brain Neuroendocrinology 49 454-461

Caldani M, Batailler M, Thiery JC and Dubois MP (19s8) LHRHimmunoreactive structures in the sheep brain Histochemistry s9 $129-139$

Caraty A and Locatelli A (1988) Effect of time after castration on secretion of LHRH and LH in the ram Joumal of Reproduction and Fertility 82 263-269

Clarke IJ and Cummins JT (I982) The temporal relationship between gonadotropin releasing hormone $(\mathrm{GnRH})$ and luteinizing hormone (LH) sectetion in ovariectomized ewes Endocrinology $111 \quad 1737-1739$

Clifton DK, Steiner RA, Resko JA and Spies HG (1975) Estrogeninduced gonadotropin release in ovariectomized rhesus monkeys and its advancement by progesterone Biology of Reproduction 13 190-194

Clifton DK, Aksel S, Bremner WJ, Steiner RA and Soules MR (1988) Statistical evaluation of coincident prolactin and luteinizing hormone pulses during the menstrual cycle Joumal of Clinical Endocrinology and Metrabolism 67 $832-838$

Currie WD, Cook SJ and Rawlings NC (1991) LH secretion in ovariectomized ewes: effects of morphine and ovarian steroid interactions with naloxone during the breeding season and anestrum Canadian Joumal of Animal Science 71 $333-342$

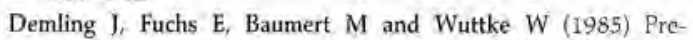
optic catecholamine, GABA and glutamate release in ovariectomized and ovariectomized estrogen-primed rats utilizing a push-pult cannula technique Neuroendocrinology $41212-218$

DietI H, Prast H and Philippu A (1993) Pulsatile release of catecholamines in the hypothalamus of conscious rats Naunyn-Schmiedeberg's Archives of Pharmacology 347 28-33

Evans NP, Dahl GE and Karsch FJ (1993). Estradiol induces qualitative and quantitative changes in the pattern of $\mathrm{GnRH}$ secretion during the pre-surge period in the ewe Program and Abstracts, 75 th Anrual Meeting of the Endocrine Society (June 1993) Abstract 1814

Fox SR, Harlan RE, Shivers BD and Pfaff DW (1990) Chemical characterization of neuroendocrine targets for progesterone in the female rat brain and pituitary Netiroendocrinology 51 276-283

Gehlert DR, Yamamura HI and Wamsley IK (1985)

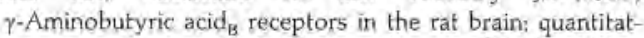
ive autoradiographic localisation using $\left[{ }^{3} \mathrm{H}\right](-)$-Baclofen Neuroscience Letters $56 \quad 183-188$

Goodman RL, Bittman EL, Foster DL and Karsch FJ (1982) Alterations in the control of luteinizing hormone pulse frequency underlie the seasonal variation in estradiol negative feedback in the ewe Biology of Reproduction $27580-589$

Herbison AE and Dyer RG (1991) Effect on luteinising hormone $(\mathrm{LH})$ secretion of $\mathrm{G} \wedge \mathrm{BA}$ receptor modulation in the medial preoptic area at the time of the proestrous $\mathrm{LH}$ surge Neuroendocrinology $53 \quad 317-320$

Herbison AE, Chapman C and Dyer RG (1991) Role of medial preoptic GABA neurones in regulating luteinising hormone secretion in the ovariectomised rat Experimental Brain Research 87 345-352

Herbison AE Augood SI and McGowan EM (1992) Expression of glutamic acid decarboxylase messenger RNA in rat medial preoptic area neurones during the oestrous cycle Molectiar Brain Research 14 310-316

Herbison AE, Robinson JE and Skinner DC (I993) Distribution of estrogen receptor-immunoreactive cells in the preoptic area of the ewe; co-localization with glutamic aciddecarboxylase but not luteinizing hormone-releasing hormone Newroendocrinology 57 751-759

Jarry H, Perschl A and Wuttke W (1988a) Further evidence that preoptic anterior hypothalamic GABAergic neurons are part of the GrRH pulse and surge generator Acta Endocrinologica 118 573-579 
Jarry H, Parschl A, Meissner H and Wuttke W (1988b) In vivo release rates of substance $P$ in the preoptic/anterior hypothalamic area of ovariectomized estrogen-primed rats: correlation with luteinizing hormone and prolactin levels Neuroscience Lellers $\mathbf{8 8} \quad$ 184-194

Jarry H, Leonhardt S and Wuttke W (1991) Gammaaminobutyric acid neurons in the preoptic/anterior hypothalamic area synchronize the phasic activity of the gonadotropin-releasing hormone pulse generator in ovariectomized rats Neuroendocrinology 53 261-267

Karsch F], Legan SJ, Ryan KD and Foster DL (1980) Imporlance of estradiol and progesterone in regulating $\mathrm{LH}$ secretion and estrous behaviour during the sheep estrous cycle Biology of Reproduction 23 404-413

Karsch FJ, Cummins JT, Thomas GB and Clarke IJ (1987) Steroid feedback inhibition of pulsatile secretion of gonadotropinreleasing hormone in the ewe Biology of Reproduction 36 $1207-1218$

Karsch FJ. Ebling FJP and Lehman MN (1989) Do catecholaminergic, neuropeptide $\gamma$, substance $P$ and GABAergic terminals innervate GnRH neurons in the sheep? Saciely of Neuroscience Abstructs 151083

Karsch FJ, Dahl GE, Evans NP, Manning JM, Mayfield KP, Moenter SM and Foster DL (1993) Seasonal changes in gonadotropin-releasing hormone secretion in the ewe: alteration in response to the negative feedback action of estradiol Biology of Reproduction 49 1377-1383

Kasa-Vubu JZ, Dahl GE, Evans NP. Thrun LA, Moenter SM. Padmanabhan V and Karsch FJ (1992) Progesterone blocks the estradiol-induced gonadotropin discharge in the ewe by inhibiting the surge of gonadotropin-releasing hormone Endocrinology 131 208-212

Kaynard AH, Malpaux B, Robinson JE, Wayne NL and Karsch FJ (1988) Importance of pituitary and neural actions of estradiol on induction of the luteinizing hormone surge in the ewe Neuroendocrinology 48 296-303

Legan SJ and Karsch FJ (1980) Photoperiodic control of seasonal breeding in ewes: modulation of the negative feedback action of estradiol Biology of Reproduction 23 I06 I-1068

Lehman MN and Karsch FJ (1993) Do gonadotropin-releasing hormone, tyrosine hydroxylase- and $\beta$-endorpinimmunoreactive neurons contain estrogen receptors? A double-label immunocytochemical study in the Suffolk cwe Endocrinology 133 887-895

Lehman MN, Robinson JE, Karsch FJ and Silverman A-J (1986) Immunocytochemical localization of luteinizing hormonereleasing hormone (LHRH) pathways in the sheep brain during anestrus and the mid-luteal phase of the estrous cycle Journal of Comparalive Neurology 244 19-35

Lehman MN, Berriman S, Gu XH, Shih ASW, Moenter SM, Evans NP, Dahl GE and Karsch FJ (1992) Progesterone blocks fos expression in gonadotropin-releasing hormone $(\mathrm{GnRH})$ neurons during the estradiol-induced GnRH surge in the ewe Society for Neuroscience Abstracts 18191

Lehman MN, Ebling FJP, Moenter SM and Karsch FJ (1993) Distribution of estrogen receptor-immunoreactive cells in the sheep brain Endocrinology $133 \quad 1579-1583$

Meyer SL and Goodman RL (1985) Neurotransmitters involved in mediating the steroid-dependent suppression of pulsatile luteinizing hormone secretion in anestrous ewes: effects of receptor antagonists Endocrinology 116 2054-2061
Moenter SM, Caraty A and Karsch F) (1990) The estradiolinduced surge of gonadotropin-releasing hormone in the ewe Endocrinology $127 \quad 1375-1384$

Moenter SM, Karsch FJ and Lehman MN (1993) Fos expression during the estradiol-induced gonadotropin-releasing hormone $(\mathrm{GnRH})$ surge of the ewe: induction in $\mathrm{GnRH}$ and other neurones Endocrinology 133 896-903

Morello H, Caligaris L, Haymal B and Taleisnik S (1989) Inhibition of proestrous LH surge and ovulation in rats evoked by stimulation of the medial raphe nucleus involves a GABA-mediated mechanism Neuroendocrinology 50 81-87

Naylor AM, Porter DWF and Lincoln DW (1989) Inhibitory effects of central LHRH on $\mathrm{LH}$ secretion in the ovariectomized ewe Neuroendocrinology 49 531-536

Robinson JE and Kendrick KM (1992) Inhibition of luteinizing hormone secretion in the ewe by progesterone: associated changes in the release of gamma-aminobutyric acid and noradrenaline in the preoptic area as measured by intracranial microdialysis Journal of Neuraendocrinalogy 4 $231-236$

Robinson JE, Kendrick KM and Lambart CE (1991) Changes in the release of gamma-aminobutyric acid and catecholamines in the preoptic/septal area prior to and during the preovulatory surge of luteinizing hormone in the ewe Journal of Neuroendocrinology 3 303-399

Robinson JE, Brown D, Chapman C and Yates JO (1993) Luteinising hormone-releasing hormone (LHRH) alters GABA release in the preoptic area (POA) of the ewe Journal of Reproduction and Fertility Abstracl Series 11 Abstract 84

Scott CJ and Clarke IJ (1993a) Inhibition of luteinizing hormone secretion in ovariectomized ewes during the breeding season by $\gamma$-aminobutyric acid (GABA) is mediated by GABA-A receptors, but not GABA-B receptors Endocrinology 132 1789-1796

Scott CJ and Clarke IJ (1993b) Evidence that changes in the function of the subtypes of the receptors for $\gamma$-amino butyric acid may be involved in the seasonal changes in the negative-feedback effects of estrogen on gonadotropinreleasing hormone secretion and plasma luteinizing hormone levels in the ewe Endocrinology 133 2904-2912

Terasawa $\mathrm{E}_{i}$ Krook C, Hei DL, Gearing M, Schultz NJ and Davis GA (1988) Norepinephrine is a possible neurotransmitter stimulating pulsatile release of luteinising hormonereleasing hormone in the rhesus monkey Endocrinology 123 $1808-1816$

Thomas GB, Pearce DT, Oldham CM, Martin GB and Lindsay DR (1988) Effects of breed, ovarian steroids and season on pulsatile secretion of $\mathrm{LH}$ in ovariectomized ewes Joumal of Reproduction and Fertility \$4 313-324

Trout WE and Malven PV (1987) Effects of exogenous estradiol$17 \beta$ and progesterone on naloxone-reversible inhibition of the release of luteinizing hormone in ewes Joumal of Animal Science 65 1602-1607

Warembourg M, Jolivet A and Milgrom E (1989) Immunohistochemical evidence of presence of estrogen and progesterone receptors in the same neurons of guinea pig hypothalamus and preoptic area Brain Research 480 I-15

Yang K, Haynes NB, Lamming GE and Brooks AN (1988) Ovarian steroid involvement in endogenous opioid modulation of LH secretion in mature ewes during the breeding and non-breeding seasons Joumal of Reproduction and Fertility 83 129-139 